\title{
Simulação do Processo de Soldagem Elétrica por Centelhamento de um Aço para Trilhos Ferroviários. Parte 1: Análise de Tensões Residuais Via Elementos Finitos
}

\author{
Rodrigo Rangel Porcaro ${ }^{1}$ (D) , Francisco Célio de Araújo ${ }^{2}$, Leonardo Barbosa Godefroid ${ }^{1}$, Geraldo Lúcio de Faria ${ }^{1}$, Luiz Leite da Silva ${ }^{3}$ \\ ${ }^{1}$ Universidade Federal de Ouro Preto (UFOP), Rede Temática em Engenharia de Materiais (REDEMAT), Ouro Preto, MG, Brasil. \\ 2 Universidade Federal de Ouro Preto (UFOP), Programa de Pós-graduação em Engenharia Civil (PROPEC), Ouro Preto, MG, Brasil. \\ ${ }^{3}$ Centro de Desenvolvimento da Tecnologia Nuclear (CDTN), Comissão Nacional de Energia Nuclear (CNEM), Belo Horizonte, MG, Brasil.
}

Como citar: Porcaro RR, Araújo FC, Godefroid LB, Faria GL, Silva LL. Simulação do processo de soldagem elétrica por centelhamento de um aço para trilhos ferroviários. Parte 1: análise de tensões residuais via elementos finitos. Soldagem \& Inspeção. 2019;24:e2412. https://doi.org/10.1590/0104-9224/SI24.12

\begin{abstract}
Resumo: Trilhos longos, soldados pelo processo Flash Butt Welding (FBW), são a realidade das ferrovias brasileiras de média e alta carga por eixo. Embora apresentem características desejáveis do ponto de vista do comportamento dinâmico da via, as soldas são regiões de descontinuidade estrutural e mecânica onde se originam tensões residuais, e que estão associadas a falhas prematuras por fadiga. Simulações numéricas termomecânicas, fisicamente nãolineares, no domínio do tempo, pelo Método dos Elementos Finitos (MEF), foram empregadas para avaliar o desenvolvimento de tensões residuais originadas durante o processo de soldagem. Uma nova abordagem para a inclusão do aporte de calor envolvido no processo é proposta. Os resultados numéricos são comparados a medidas experimentais de tensões residuais superficiais e aspectos macrográficos das juntas, incluindo largura da Zona Termicamente Afetada (ZTA) e dados de taxas de resfriamento. Os resultados mostram boa correlação entre as análises numéricas e medidas experimentais de tensões residuais. Aspectos fundamentais relacionados ao desenvolvimento de tensões residuais são esclarecidos a partir da correlação entre análises numérica e experimental. Ademais, verifica-se que os modelos computacionais podem ser utilizados na previsão de pontos críticos para nucleação de trincas por fadiga e/ou avaliar efeitos de variáveis de processo sobre o campo de tensões residuais.
\end{abstract}

Palavras-chave: Soldagem por centelhamento; Método dos Elementos Finitos; Metalurgia da soldagem; Tensões residuais.

\section{Simulation of Flash-Butt Welding Process of a Railway Steel. Part 1: Residual Stress Analysis Via FEM}

\begin{abstract}
Long rails, welded by the Flash-Butt Welding (FBW) process, are the reality of the Brazilian railroads for medium and high axle loads. Although they present desirable characteristics concerning the dynamic behavior of the track, welded joints are regions of structural and mechanical discontinuity where high residual stresses originate, and, consequently, premature fatigue failures may take place. This paper employs the Finite Element Method (FEM) to carry out transient, physically non-linear thermo-mechanical analyses to evaluate residual stresses evolved in the welding process. A new approach is proposed to take into account the heat input involved in the process. The numerical results are compared to experimentally measured surface residual stresses, and to the macrographic joint aspects, including the HAZ width and cooling rate data. The results show a good correlation between the numerical and experimental measurements of residual stresses. Fundamental aspects related to the development of residual stresses are clarified, correlating numerical and experimental analyses. In addition, it is verified that the computational models can be used to predict critical crack nucleation points by fatigue, and/or to evaluate effects of process parameters on the residual stress field.
\end{abstract}

Key-words: Flash-butt welding; The Finite Element Method; Welding metallurgy; Residuals stresses. 


\section{Introdução}

O aumento crescente na demanda pelo transporte ferroviário tem imposto condições cada vez mais severas de solicitação às ferrovias. A necessidade de aumentar o tráfego de composições, a velocidade e a carga por eixo impulsiona o desenvolvimento de tecnologias específicas para a construção das linhas férreas [1]. Um exemplo é a utilização de trilhos longos soldados (TLS) na construção de ferrovias continuamente soldadas. Linhas ferroviárias continuamente soldadas pelo processo de soldagem elétrica por centelhamento (flash butt welding - FBW) são a realidade da malha ferroviária Brasileira para transporte de grãos e bens minerais [2].

Apesar de suas características desejáveis, a prática de união de trilhos por soldagem FBW introduz na ferrovia pontos susceptíveis à nucleação e propagação de trincas por fadiga, por representarem uma descontinuidade microestrutural com diminuição da dureza, da resistência mecânica e da resistência ao desgaste [3]. Além da introdução de tensões residuais, que também aceleram os processos de degradação por fadiga [4-6]. A soldagem pelo processo FBW pode ainda introduzir descontinuidades estruturais, por exemplo, falta de fusão, inclusões, dentre outras.

Em trabalho anteriormente publicado nesta revista, Porcaro et al. [7] apresentaram detalhada caracterização estrutural e mecânica de trilhos ferroviários de aço perlítico soldados por centelhamento elétrico. Os resultados da análise morfológica da perlita em toda a extensão da ZTA mostraram que os ciclos termomecânicos do processo de soldagem promovem a variação do tamanho de colônias, espaçamento interlamelar e esferoidização parcial da cementita, com significativa variação de microdureza. Além da presença de concentrador de tensão na superfície da alma das juntas devido ao mau acabamento após o corte de rebarbas, o que geralmente está associado a falhas precoces por fadiga do tipo Horizontal Split Web (HSW) [8,9].

A avaliação das tensões residuais em juntas de trilhos obtidas por centelhamento elétrico tem sido feita pela técnica do furo central com extensometria $[6,10,11]$. Além disso, alguns trabalhos utilizando simulações por elementos finitos têm sido publicados com duas abordagens principais: (i) simulação eletro-termo-mecânica; e (ii) simulação termo-mecânica. No primeiro tipo de abordagem, tenta-se uma simulação completa do fenômeno, incluindo-se, no modelo eletrotérmico transiente, a geração de calor por efeito Joule. Os valores nodais de temperatura no modelo são posteriormente utilizados como dados de entrada em um modelo mecânico com objetivo de simular o desenvolvimento de tensões residuais [12-14]. No segundo tipo (simulação termo-mecânica), um input de calor genérico equivalente àquele gerado durante a soldagem por centelhamento é aplicado como condição de contorno em uma simulação térmica transiente, sendo os valores de temperatura nos nós do modelo, em cada passo de tempo, posteriormente utilizados em um modelo mecânico para avaliar o desenvolvimento de tensões residuais [11,15-17].

Skyttebol et al. [10] avaliaram como o estado de tensões residuais decorrente do processo de soldagem por centelhamento influencia no crescimento de trincas por fadiga em juntas de trilhos. Mansouri e Monshi [6] atribuíram o desenvolvimento de tensões residuais trativas, na alma de juntas, a uma maior densidade de corrente elétrica nesta região, fato este que estaria relacionado à maior relação área/volume em relação ao boleto e patim. Em trabalho recente, Weingrill et al. [14] monitaram com termopares a evolução de temperaturas em todas as regiões de trilho ferroviário durante a soldagem elétrica por centelhamento. Os resultados reportados corroboram a hipótese levantada por Mansouri e Monshi [6], pois a temperatura de pico na alma foi superior a $1400{ }^{\circ} \mathrm{C}$ e, no boleto e patim, não ultrapassou $1355{ }^{\circ} \mathrm{C}$. Tawfik et al. [5] sugeriram e apresentaram resultados numéricos de tratamentos térmicos rápidos pós-soldagem para reduzir o nível de tensões residuais decorrentes da soldagem por centelhamento de trilhos.

Neste contexto, medidas de tensões residuais superficiais em juntas de trilhos ferroviários soldados por FBW foram realizadas a partir da técnica do furo central com extensometria. Além disso, a partir de resultados previamente publicados de caracterização estrutural e mecânica das juntas $[7,18]$ e do importante trabalho de monitoramento de ciclos térmicos realizado por Weingrill et al. [14], simulações numéricas termomecânicas pelo Método dos Elementos Finitos foram empregadas para avaliar o desenvolvimento de tensões residuais nos trilhos, com uma nova abordagem para a inclusão do aporte de calor na análise, baseada em uma fonte distribuída no volume correspondente à região de solda associada a um fluxo superficial adicional de calor. Os resultados mostram como a associação de análises experimentais e simulações numéricas permite compreender os mecanismos envolvidos no desenvolvimento de tensões residuais em juntas de trilhos ferroviários soldados por centelhamento elétrico.

\section{Materiais e Métodos}

O trabalho se dividiu entre análises experimentais e numéricas, na Figura 1 apresenta-se um fluxograma que resume as etapas realizadas, cujo detalhamento será apresentado nas seções seguintes. 
Simulações Numéricas por elementos finitos

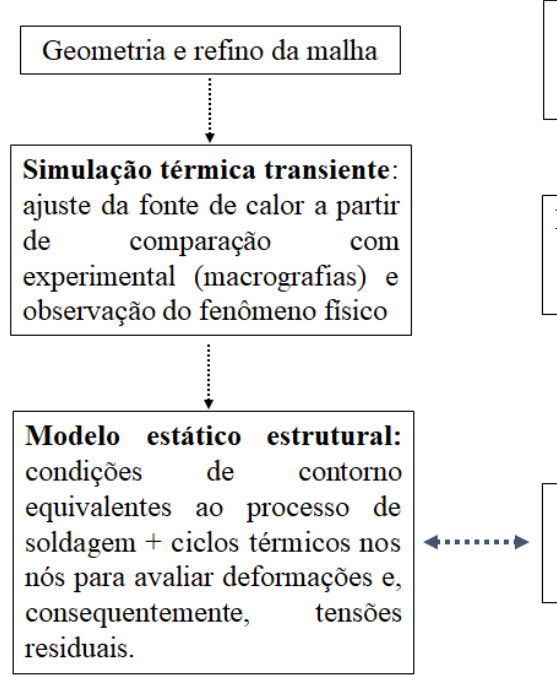

Experimental

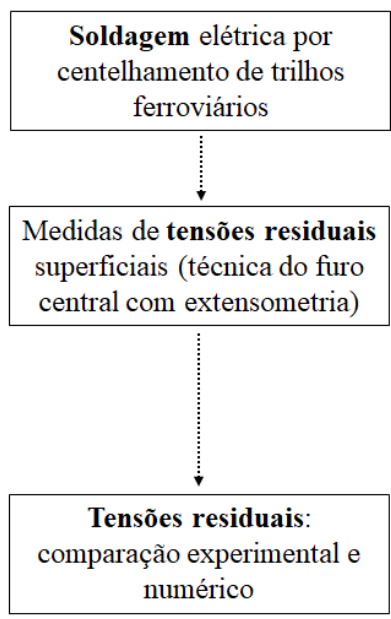

Figura 1. Fluxograma das etapas realizadas no desenvolvimento do trabalho, associando análises numéricas e medidas experimentais. As macrografias foram obtidas em trabalho anterior [7].

\subsection{Materiais}

O material utilizado no estudo é um aço para trilhos ferroviários do tipo intermediário que atende à Norma AREMA [19] com perfil TR-57, ou seja, com densidade linear de aproximadamente $57 \mathrm{~kg} / \mathrm{m}$. Os trilhos são importados e foram soldados pelo processo FBW em um estaleiro brasileiro, segundo os procedimentos padrão para ferrovias de baixa/média carga por eixo. Os parâmetros de soldagem são apresentados na Tabela 1. As juntas não sofreram resfriamento acelerado após a soldagem, sendo resfriadas naturalmente ao ar. Foram amostradas 3 juntas com $600 \mathrm{~mm}$ de comprimento após a etapa de acabamento no estaleiro para medidas de tensões residuais.

Tabela 1. Parâmetros de soldagem controlados para o trilho intermediário TR-57.

\begin{tabular}{|c|c|c|}
\hline \multirow{2}{*}{$\begin{array}{l}\text { Parâmetro controlado na soldagem } \\
\text { Intensidade e duração do flash inicial }\end{array}$} & \multicolumn{2}{|c|}{ Valores } \\
\hline & $77,4 \mathrm{kA}$ & $20 \mathrm{~s}$ \\
\hline Número de pulsos de corrente de pré-aquecimento e duração dos pulsos & 10un. & $3,8 \mathrm{~s}$ \\
\hline Intensidade dos pulsos de pré-aquecimento & 45-70kA & - \\
\hline Intensidade da força durante os pulsos de pré-aquecimento & $106 \mathrm{kN}$ & - \\
\hline Intensidade e duração do flash final & $38,3 \mathrm{kA}$ & $14,4 \mathrm{~s}$ \\
\hline Intensidade da força de recalque & $477 \mathrm{kN}$ & - \\
\hline Curso total após recalque & $37-45 \mathrm{~mm}$ & - \\
\hline
\end{tabular}

\subsection{Tensões residuais superficiais}

As tensões residuais superficiais em três juntas soldadas de trilhos foram avaliadas utilizando-se o método do furo central, segundo a Norma ASTM E837 [20]. Foram estimadas as tensões residuais em quatro pontos sobre a linha vertical central da junta soldada (Figura 2a), dos quais três pontos na alma (um na altura da linha neutra e dois afastados 20mm dela) um outro ponto no centro do boleto. Para a preparação superficial das regiões onde os extensômetros foram colados, foi utilizada uma retífica manual de alta rotação para remover o restante da rebarba decorrente do processo de soldagem. De modo a reduzir os efeitos da retificação no estado de tensão do material, um ataque com Nital a $5 \%$ foi realizado sobre a superfície preparada, como recomendado em [20].

Os ensaios para medição das tensões residuais superficiais foram realizados no Centro de Desenvolvimento da Tecnologia Nuclear (CDTN), situado no campus da UFMG, em Belo Horizonte. Na Figura 2b há o detalhe de um strain gage ligado aos terminais da unidade de registro das resistências elétricas, além de broca cônica odontológica e turbina a ar comprimido utilizadas para realização de furo. Para análise dos dados obtidos, verificação da validade dos furos/medidas e estimativa de tensões residuais segundo a Norma ASTM E837 [20], foi utilizado o software H-Drill. Para os cálculos, 
considerou-se um módulo de elasticidade igual a 208GPa e coeficiente de Poisson igual a 0,3 [12]. O limite de escoamento foi obtido em ensaios de tração das juntas soldadas (640MPa [18]).

Para a realização dos ensaios, strain gages modelo KFG-1.5-120-D28-11 do fabricante Kyowa foram utilizados. Os furos foram realizados com broca cônica odontológica (diâmetro de 1,59mm) em incrementos de 0,05mm até a profundidade total de $1 \mathrm{~mm}[20]$.
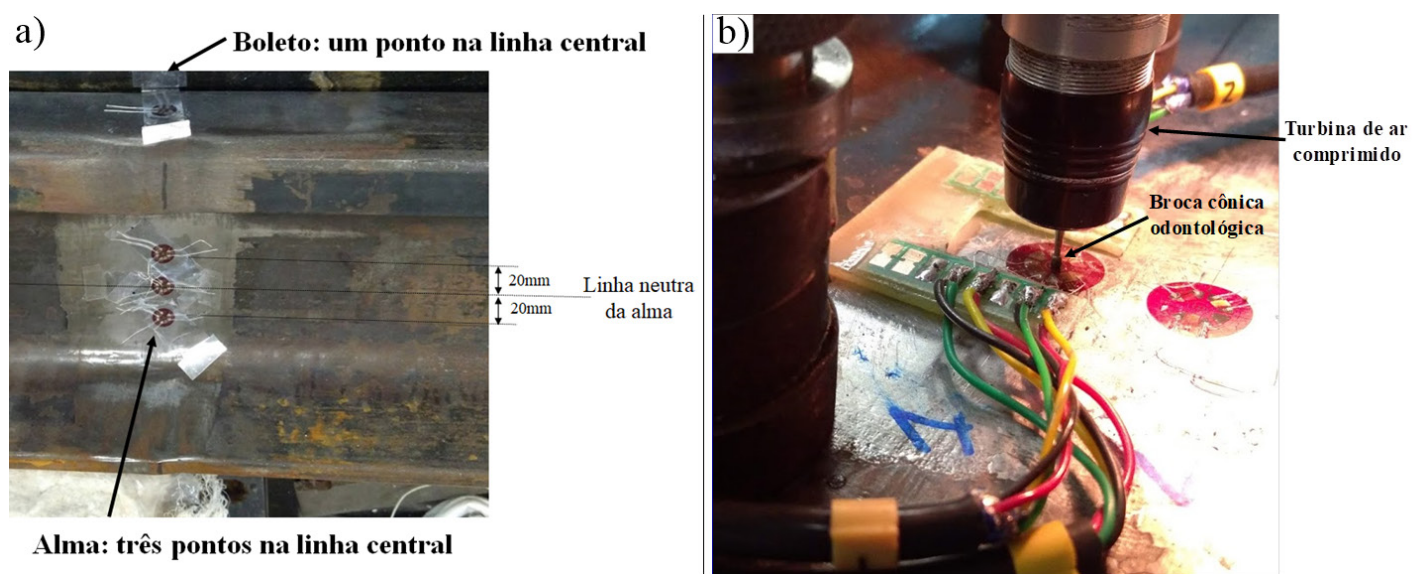

Figura 2. (a) Esquema de regiões para medidas de tensões residuais em junta de trilho ferroviário soldado por centelhamento; (b) Detalhe de extensômetro ligado aos terminais para registro, broca e turbina a ar comprimido.

\subsection{Simulações numéricas por elementos finitos}

O desenvolvimento de tensões residuais durante o processo de soldagem elétrica por centelhamento foi simulado numericamente via Método dos Elementos Finitos. A primeira etapa das simulações foi a modelagem do componente em CAD (Computer Aided Design) no software Ansys ${ }^{\circledR}$ Design Modeler ${ }^{\circledR}$. Todos os detalhes geométricos foram estabelecidos segundo a Norma AREMA [19]. Na Figura 3 apresenta-se o modelo, que possui simetria longitudinal, de modo a reduzir o número de graus de liberdade e, assim, o tempo computacional para as simulações. O modelo possui comprimento total igual a $260 \mathrm{~mm}$, e um estudo de refinamento da malha, não estruturada, formada por elementos tetraédricos, foi realizado a partir da convergência dos valores de tensões equivalentes de von-Mises (variação menor que $5 \%$ a partir do aumento do número de nós) e minimização do erro na resposta estrutural. Uma vez que o modelo estático estrutural apresenta não linearidade mais significativa que o modelo térmico, o primeiro foi utilizado para o estudo de refinamento da malha. Como parâmetros de refinamento adotaram-se tamanho global da malha de $10 \mathrm{~mm}$ e, na região de interesse correspondente à solda, submetida a maior fluxo térmico e gradientes de tensões, um refinamento igual a 2mm, resultando em 52056 elementos e 77953 nós (Figura 3).

Uma vez que, para o problema em questão, as deformações são pequenas e as geometrias de referência não sofrem alterações significativas com as tensões/deformações de origem térmica, estratégia de solução baseada em análises térmica e mecânica fisicamente desacopladas se aplica satisfatoriamente, ou seja, primeiro resolve-se o problema de condução de calor no trilho e, na sequência, o problema de tensões de origem térmica [21]. Desse modo, reduz-se o tempo total de processamento do modelo se comparado à análise termo-mecânica acoplada.

O estudo termomecânico deve levar em consideração a deformação plástica durante o aquecimento/resfriamento, ou seja, trata-se de um problema fisicamente não linear. Para uma correta avaliação das tensões e deformações, foi criado um novo material na biblioteca do software de simulação. As propriedades físicas do material relacionadas ao modelo térmico (condutividade térmica e capacidade térmica em função da temperatura) foram as mesmas utilizadas por Cai et al. [16]. Como reportado por $\mathrm{Ma}$ et al. [11], as transformações de fases exercem significativa influência sobre o estado final de tensões residuais em juntas de trilhos soldados por FBW, no entanto, aqueles autores consideraram a formação de martensita. Uma vez que as taxas de resfriamento reportadas para esse processo de soldagem são próximas a $1^{\circ} \mathrm{C} / \mathrm{s}$ [14] e somente perlita foi encontrada na caracterização estrutural das juntas $[7,18]$, não foi considerado no modelo a transformação martensítica e/ou bainítica. Além disso, a influência das transformações de fases reconstrutivas nos modelos numéricos é muito pouco significativa. Sendo assim, considerou-se um valor médio igual a $3 \times 10^{-5} /{ }^{\circ} \mathrm{C}$ para o coeficiente de expansão térmica instantâneo, calculado a partir da derivada da deformação relativa em ensaios de dilatometria aplicado ao material [18] e com auxílio do software Origin ${ }^{\circledR} 9$ [22]. 


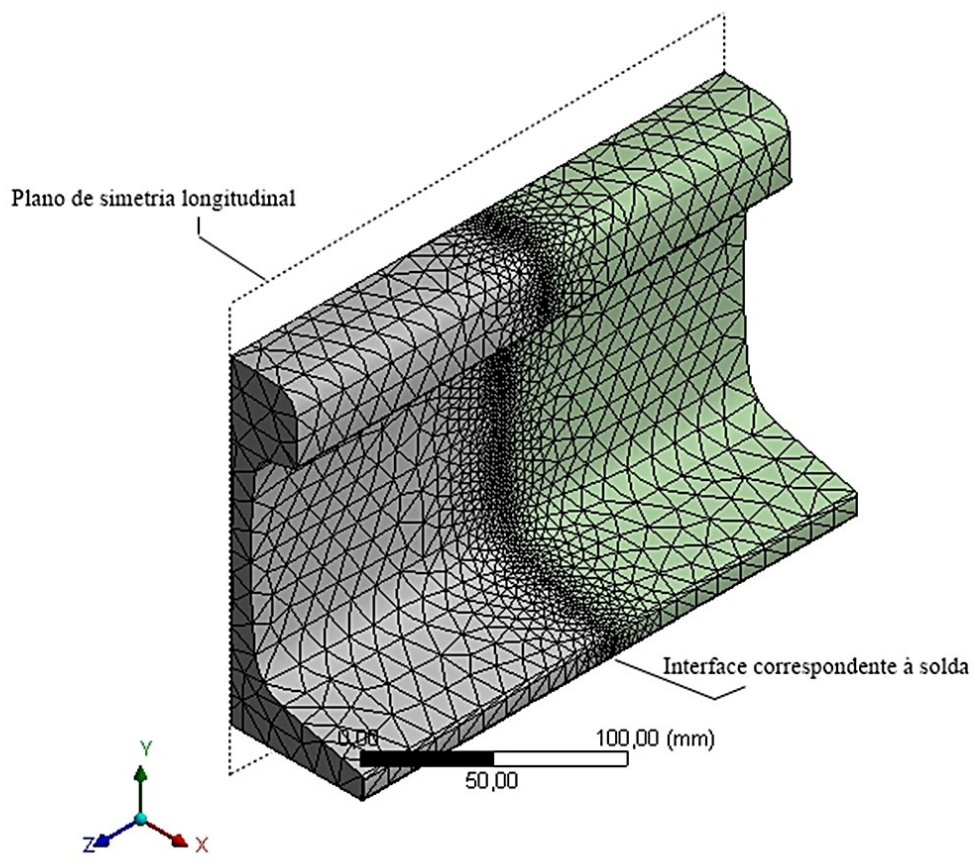

Figura 3. Malha de elementos finitos adotada para trilho ferroviário com perfil TR-57 em simulações térmicas e estáticas estruturais.

Para considerar as propriedades mecânicas em função da temperatura foi utilizado o modelo bilinear isotropic hardening Ansys [23]. Os valores do módulo de elasticidade, limite de escoamento e módulo tangente foram os mesmos usados por Haibatollahi e Tehrani [13], pois o aço simulado por aqueles autores possui propriedades mecânicas próximas ao aço perlítico intermediário tratado neste trabalho.

\subsubsection{Modelo térmico}

A simulação térmica foi utilizada para obter a variação de temperatura (ciclo térmico) em cada nó do modelo, a partir da introdução de uma fonte de calor superficial genérica na interface dos trilhos. Para determinar a resposta desse problema térmico no domínio do tempo, análise não-linear física via elementos finitos foi realizada. Nesta, empregou-se o módulo Transient Thermal do software Ansys ${ }^{\circledR}$ e adotou-se o elemento finito 'SOLID 87' (tetraedro parabólico), com 10 nós por elemento [23].

A fonte de calor equivalente à soldagem elétrica por centelhamento foi simulada por uma fonte de calor superficial simples, de modo semelhante ao adotado em [11,15-17]. No entanto, diferentemente da idealização adotada por aqueles autores, a fonte de calor superficial equivalente, neste trabalho, não foi uniformemente distribuída na interface do modelo, pois os trabalhos de Mansouri e Monshi [6], Weingrill et al. [14] e Porcaro et al. [7] mostraram que a alma possui as maiores temperaturas de pico durante a soldagem FBW, sendo este um fator fundamental no desenvolvimento de tensões residuais na direção vertical.

Baseado nos parâmetros de soldagem apresentados na Tabela 1, a fonte de calor superficial foi aplicada no modelo por um tempo igual a 80s. Diferentes valores de potência foram testados para simular, de forma aproximada, o aporte de calor equivalente ao processo de soldagem por centelhamento. O processo de ajuste da fonte de calor equivalente (fluxo térmico em $\mathrm{W} / \mathrm{mm}^{2}$ ) levou em conta três fatores: (i) largura da região aquecida acima de $727{ }^{\circ} \mathrm{C}$ da mesma ordem de grandeza das medidas em análises macrográficas correspondentes à ZTA; (ii) temperaturas de pico na interface da mesma ordem de grandeza daqueles reportados por Weingrill et al. [14] para alma, boleto e patim; e (iii) a partir das análises dilatométricas realizadas no aço do presente trabalho em condições de resfriamento semelhantes ao reportado para a soldagem elétrica por centelhamento (em torno de $1^{\circ} \mathrm{C} / \mathrm{s}$ entre $800^{\circ} \mathrm{C}$ e $500{ }^{\circ} \mathrm{C}$, Porcaro et al. [18]).

As condições de contorno para o modelo térmico são apresentadas na Figura 4. Como condição inicial foi adotada temperatura uniforme igual a $25{ }^{\circ} \mathrm{C}$ em todo o modelo. Também foram consideradas as perdas térmicas por radiação e convecção, sendo o coeficiente de convecção em função da temperatura igual ao reportado por Ma et al. [11]. Um modelo de radiação padrão do software foi usado para a simulação de radiação com temperatura ambiente igual a $25^{\circ} \mathrm{C}$ [23].

Nas extremidades do modelo, Figura 4, superfícies correspondentes aos planos YX e ao plano de simetria YZ, foram aplicadas condições de contorno do tipo isolamento perfeito, ou seja, não há fluxo de calor através desses planos. Para a análise térmica não linear no domínio do tempo [24], incrementos de tempo iguais a 0,1s foram utilizados, os quais foram por sua vez considerados na definição da carga térmica do modelo estrutural quasi-estático fisicamente não-linear. 


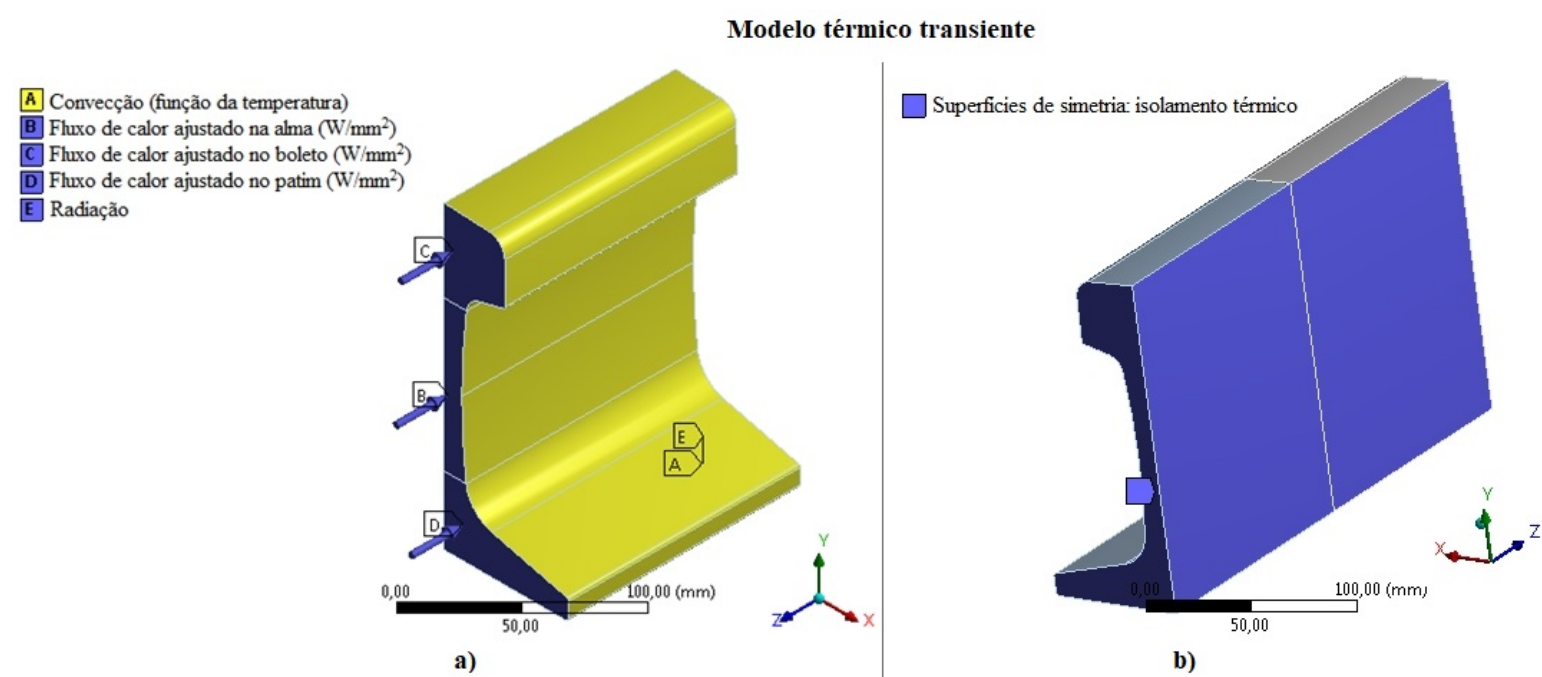

Figura 4. (a) Condições de contorno para o modelo térmico equivalente ao processo FBW; (b) Superfícies correspondentes aos planos de simetria com isolamento térmico perfeito.

\subsubsection{Modelo estático estrutural}

Os resultados de variação de temperatura em função do tempo em cada nó do modelo térmico foram utilizados como dados de entrada para o modelo mecânico no software Ansys ${ }^{\circledR}$, no módulo Static Structural. As condições de contorno do modelo são apresentadas na Figura 5. Os deslocamentos de todos os nós do plano $Y X$ foram restringidos nas direções $Z$ e $Y$, uma vez que durante a soldagem, o eletrodo fixo da máquina impede movimentos do trilho (plano A da Figura 5). Os deslocamentos na direção $X$ no plano de simetria $Y Z$ também foram restringidos. Ressalta-se que a extremidade oposta ao plano A do modelo (Figura 5) possui todos os deslocamentos livres, pois corresponde ao trilho ligado ao eletrodo móvel durante o processo de soldagem por centelhamento. Também não se considerou a força de forjamento aplicada ao final da soldagem, estratégia comumente adotada em simulações de soldagem por centelhamento elétrico [11-17].

A região de contato entre os dois segmentos de trilho foi do tipo shared topology [23], ou seja, do ponto de vista de comportamento mecânico, o modelo global de análise compreende duas subestruturas perfeitamente acopladas na interface dos trilhos.

O problema estático estrutural é fisicamente não-linear, e para a sua resolução via MEF, também empregou-se o software Ansys ${ }^{\circledast}$. De modo coerente com a análise térmica, adotou-se aqui, na análise elastoplástica 3D do sólido, o elemento finito 'SOLID 187' (tetraedro parabólico), com 10 nós por elemento [23].

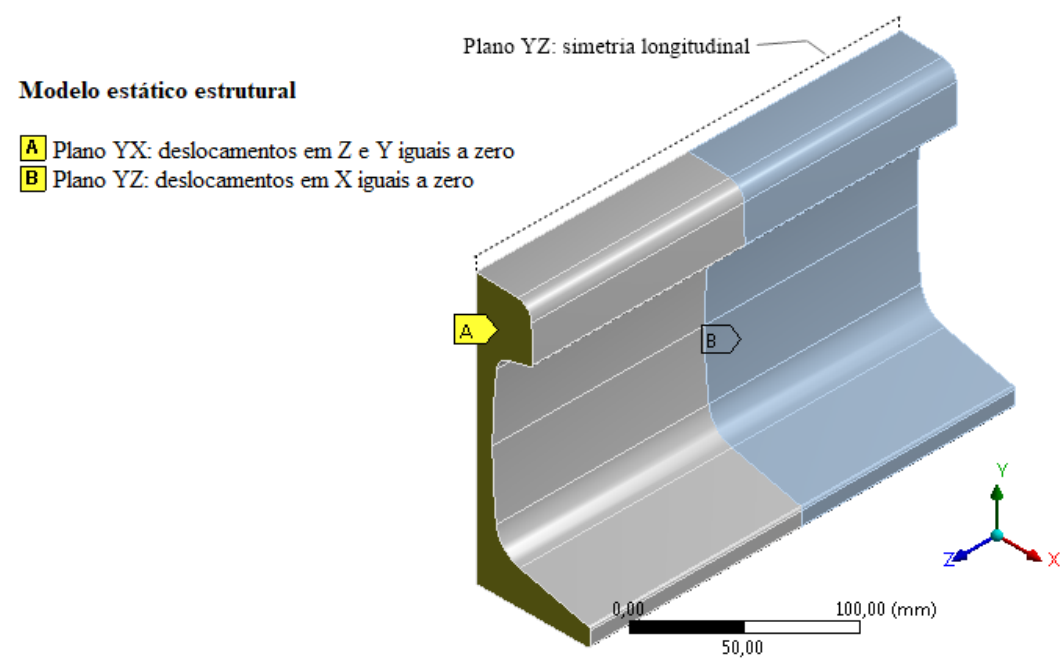

Figura 5. Condições de contorno para o modelo estático estrutural equivalente ao processo FBW. 


\section{Resultados e Discussão}

\subsection{Tensões residuais}

Na Figura 6a apresentam-se os valores de tensões residuais normais medidos nos quatro pontos indicados (Figura 6b) e em relação ao sistema de referência adotado. Os valores individuais dos furos validados são apresentados na Tabela 2. Segundo a Norma ASTM E837 [20], só podem ser considerados válidos para os cálculos, os furos nos quais as microdeformações obtidas nos três extensômetros da roseta apresentaram crescimento contínuo e sem variações abruptas após cada incremento de $0,05 \mathrm{~mm}$ na profundidade do furo. Os motivos para a não validação incluem dificuldades na execução do furo, fratura de broca, desalinhamentos, erros de leitura e colagem dos extensômetros, entre outros [25].
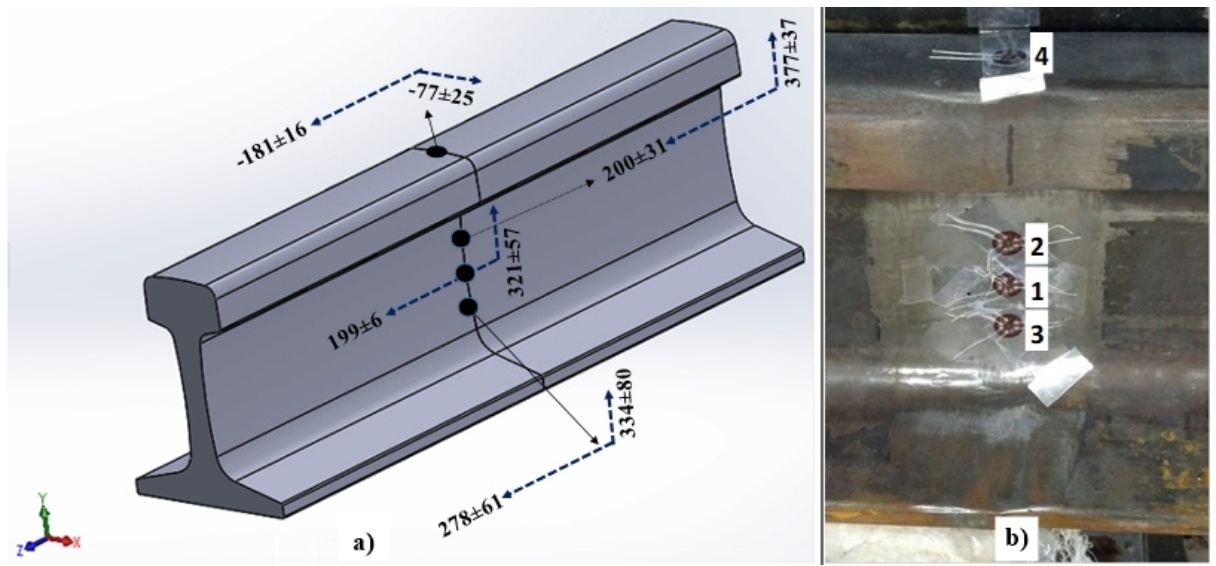

Figura 6. (a) Valores médios de tensões residuais normais (MPa) obtidos a partir da técnica do furo; (b) Pontos de medida de tensões residuais na alma $(1,2,3)$ e boleto (4).

Tabela 2. Resultados experimentais de tensões residuais normais em juntas soldadas por centelhamento elétrico em trilho ferroviário intermediário. Sistema de referência na Figura 5a.

\begin{tabular}{|c|c|c|c|c|c|c|c|c|}
\hline \multirow{3}{*}{ Amostras } & \multicolumn{8}{|c|}{ Tensões residuais normais (MPa) } \\
\hline & \multicolumn{2}{|c|}{ Posição 1} & \multicolumn{2}{|c|}{ Posição 2} & \multicolumn{2}{|c|}{ Posição 3} & \multicolumn{2}{|c|}{ Posição 4} \\
\hline & $\sigma_{\mathrm{y}}$ & $\sigma_{\mathrm{z}}$ & $\sigma_{\mathrm{y}}$ & $\sigma_{\mathrm{z}}$ & $\sigma_{\mathrm{y}}$ & $\sigma_{\mathrm{z}}$ & $\sigma_{\mathrm{x}}$ & $\sigma_{\mathrm{z}}$ \\
\hline 01 & 362 & 195 & 400 & 164 & 278 & 235 & -49 & -167 \\
\hline 02 & NV & NV & 334 & 215 & NV & NV & -94 & -177 \\
\hline 03 & 281 & 204 & 398 & 220 & 391 & 322 & -90 & -199 \\
\hline Média & 321,5 & 199,5 & 377,3 & 200,0 & 334,5 & 278,5 & $-77,7$ & $-181,0$ \\
\hline Desvio padrão & 57 & 6 & 37 & 31 & 80 & 61 & 25 & 16 \\
\hline
\end{tabular}

NV = furo não validado segundo os critérios da Norma ASTM E837 [20].

Um ponto que merece destaque em relação aos dados de tensões residuais experimentais é o fato de que o estado geral de tensões superficiais nas juntas soldadas é determinado pelas componentes de tensões normais, uma vez que os valores de tensões cisalhantes obtidos foram desprezíveis. Os resultados de tensões residuais obtidos nas juntas de trilho intermediário seguiram a mesma tendência de estudos anteriores [5,6,10-17], com tensões normais trativas nos sentidos longitudinal e vertical na região da alma e tensões compressivas no boleto. O estado de tensão obtido pode ser explicado pelo desenvolvimento de intensa deformação de origem térmica, com deformação plástica localizada na alma durante o ciclo de aquecimento devido a sua maior temperatura durante o processo de soldagem. Por outro lado, o boleto e patim, apresentam temperaturas menores durante a soldagem por centelhamento, restringindo a expansão da alma durante o aquecimento. No resfriamento, devido às deformações plásticas, sobretudo na região da alma, um estado de tensão trativo surge nesta região e é contrabalançado por tensões compressivas no boleto e patim [6,15].

Diferentes valores de tensões residuais em juntas de trilhos obtidas pelo processo FBW têm sido reportados na literatura, no entanto, uma vez que o nível de tensões residuais depende de uma série de parâmetros de soldagem, condições de resfriamento pós-soldagem, aços dos trilhos e técnica utilizada para as medidas, não se pode esperar valores iguais para diferentes juntas soldadas [26]. 
Sabe-se que as tensões residuais trativas na alma, associadas a concentradores de tensão oriundos de rebarba e/ou descontinuidades de soldagem nesta região são responsáveis pelo desenvolvimento de falhas por fadiga do tipo HSW [5,7-10]. Um dos aspectos mais importantes em relação a tensões residuais introduzidas na alma de juntas de trilhos ferroviários é o fato de que este estado de tensão praticamente não se altera durante a vida útil do material, mesmo com a introdução de carregamento externo elevado devido à passagem de composições [10].

\subsection{Simulações numéricas}

\subsubsection{Modelos térmicos}

Os modelos iniciais simulados utilizaram fonte de calor superficial simples na interface dos trilhos. Os valores de densidade de potência, aplicados separadamente nas três regiões do trilho, foram ajustados de modo a obter temperaturas de pico semelhantes às medidas por Weingrill et al. [14], resultando em valores iguais a $3,2 \mathrm{~W} / \mathrm{mm}^{2}, 3,5 \mathrm{~W} / \mathrm{mm}^{2}$ e $3,2 \mathrm{~W} / \mathrm{mm}^{2}$, para boleto, alma e patim, respectivamente, por 80 s. 0 resultado de distribuição de temperaturas máximas é mostrado na Figura 7.

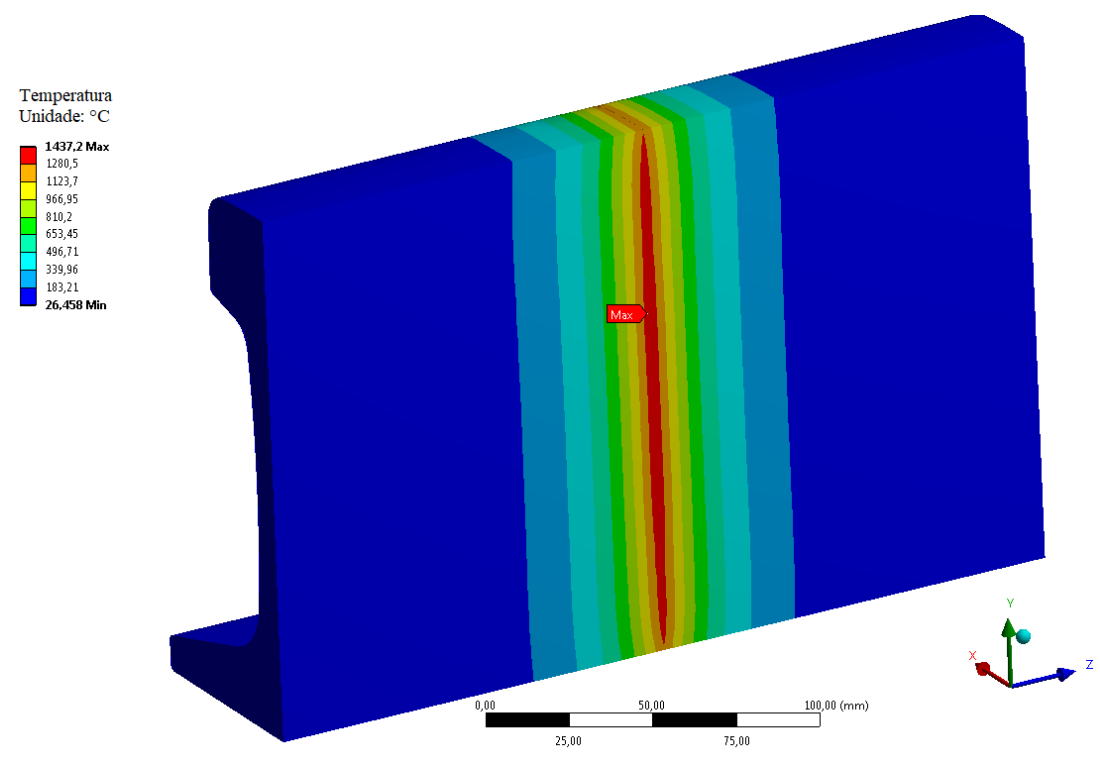

Figura 7. Distribuição de temperaturas em junta soldada por FBW obtida pelo MEF.

Do ponto de vista térmico, as soluções utilizando este modo de aporte de calor foram semelhantes às reportadas em trabalhos anteriores, que utilizaram abordagem semelhante [11,16]. No entanto, observou-se que os gradientes de temperatura obtidos entre a interface dos trilhos e a região adjacente da ZTA foram muito elevados, além disso, a largura da região aquecida acima de $700{ }^{\circ} \mathrm{C}$ não foi semelhante ao medido experimentalmente nas análises macrográficas (largura da ZTA) [7]. Os dados de temperatura foram exportados para modelos estáticos estruturais iniciais e percebeu-se que os valores elevados dos gradientes de temperatura produziram estados de tensões residuais superestimados no componente, em comparação aos obtidos experimentalmente. Tensões superestimadas em relação a medidas experimentais também foram obtidas em simulações reportadas anteriormente $[11,16]$.

A partir desta avaliação dos resultados iniciais e, levando em consideração que durante o processo de soldagem elétrica por centelhamento a maior parte do calor é gerado por efeito Joule (no volume do material), um novo modelo de fonte de calor foi definido para as simulações térmicas. Neste caso, utilizou-se uma fonte de calor do tipo internal heat generation, disponível no programa de elementos finitos, de modo a aproximar o problema numérico da situação física real. Como mostrado na Figura 8, um corpo intermediário com 30mm de comprimento foi introduzido entre os dois segmentos de trilho, que permitiu a aplicação individual das condições de contorno térmicas. O comprimento do corpo intermediário foi definido a partir de análises macrográficas apresentadas em [7]. As interfaces utilizadas entre as partes sólidas do modelo foram do tipo Shared Topology, com continuidade de malha entre os corpos. 
a)

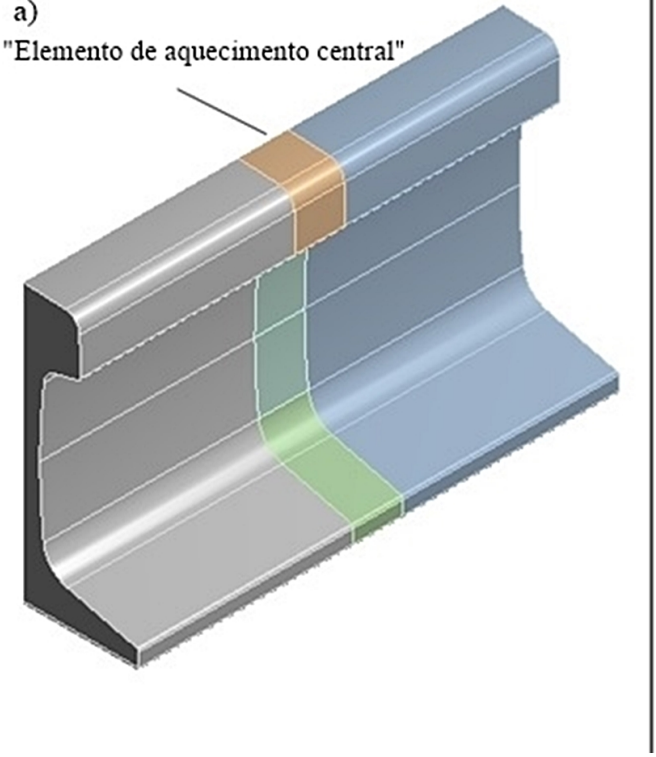

b)

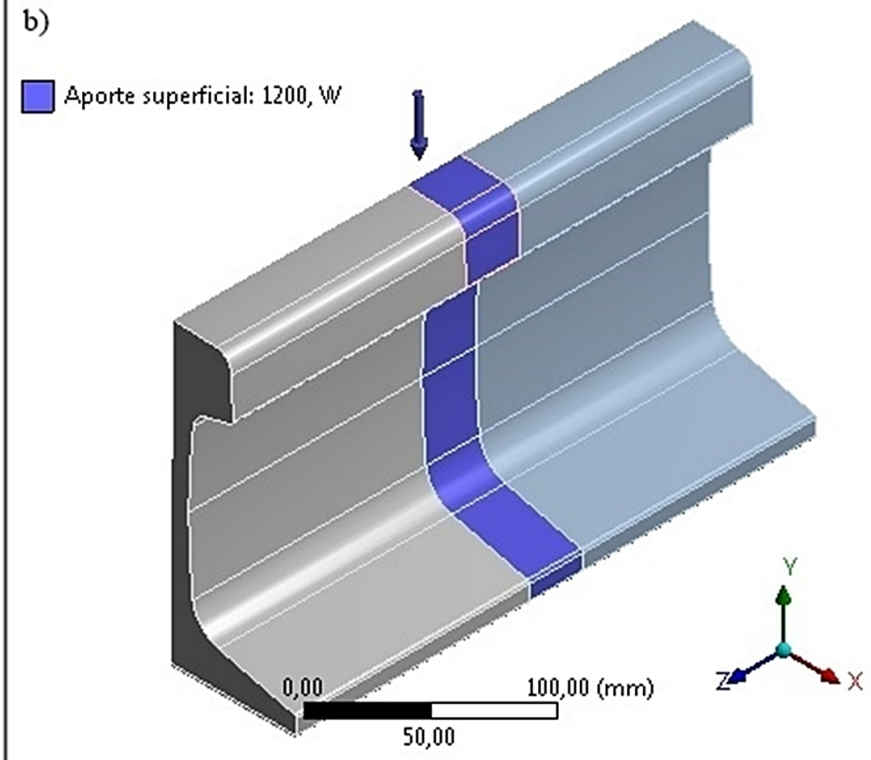

Figura 8. Representação em CAD da geometria do modelo do trilho ferroviário. (a) Em destaque um corpo intermediário com 30mm, utilizado como elemento de aquecimento volumétrico; (b) Destaque para aporte de calor superficial.

As condições finais de aporte térmico adotadas foram então modificadas, e estabelecerem-se valores de geração de calor volumétrico iguais a $0,125 \mathrm{~W} / \mathrm{mm}^{3}$ para o boleto e patim, e iguais a $0,14 \mathrm{~W} / \mathrm{mm}^{3}$ para a alma, por 80 s. Além disso, conforme discutido por Mansouri e Monshi [6] e os resultados obtidos na caracterização metalográfica das juntas de trilho intermediário em trabalhos anteriores [7,18], durante o processo de soldagem por FBW, a corrente elétrica é conduzida mais facilmente nas regiões superficiais do material, portanto, as superfícies dos trilhos apresentam maiores temperaturas que o interior. Uma vez que, nas simulações, o calor foi gerado no volume do corpo central, e ocorrem trocas térmicas por radiação e convecção nas superfícies, o interior do material acaba apresentando maior temperatura que a superfície, como ilustrado na Figura 9. Como consequência deste gradiente de temperatura, as simulações preliminares de tensões residuais indicaram tensões residuais compressivas na superfície da alma soldada na direção longitudinal, (eixo Z). Este resultado não tem sentido físico, uma vez que a maior parte dos autores obteve tensões residuais trativas nos dois sentidos na superfície da alma, sobre a linha neutra. Resultados semelhantes do ponto de vista de tensões longitudinais foram obtidos por Ma et al. [11]. Os autores não explicaram a origem das tensões residuais compressivas na superfície da linha central na região da alma. Porém, ao se analisar os resultados obtidos aqui, juntamente com a observação dos perfis térmicos apresentados, pode-se atribuir este estado de tensões residuais ao mesmo fenômeno.

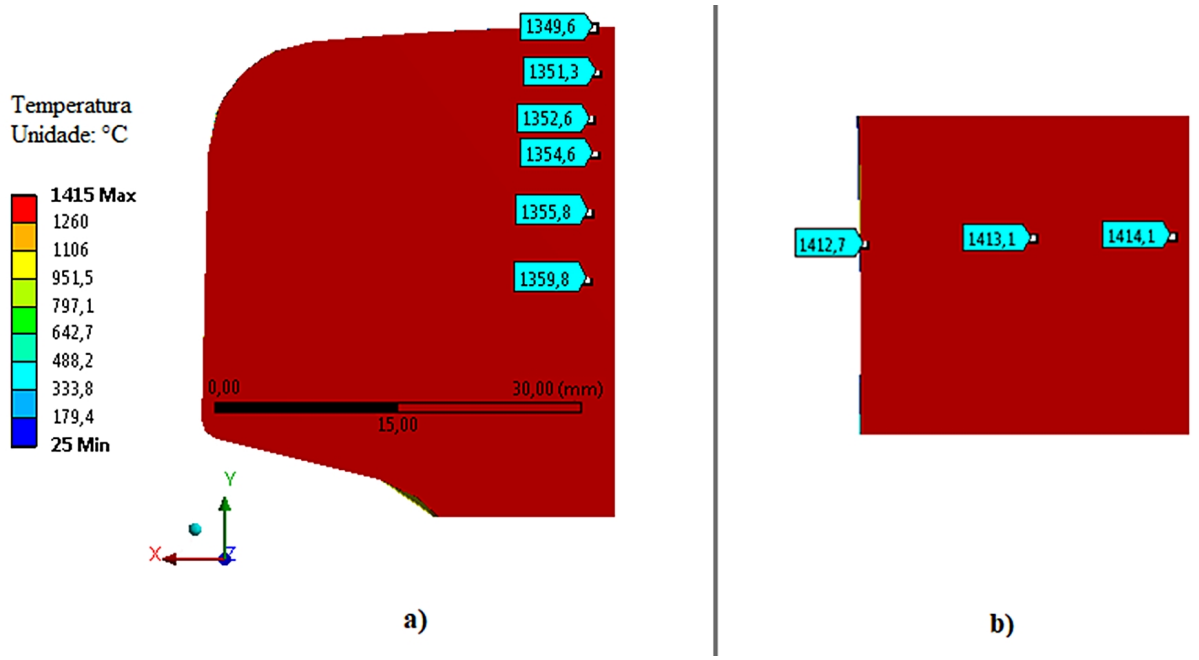

Figura 9. Distribuição de temperaturas via MEF sob fonte de calor volumétrica no elemento de aquecimento central: (a) no boleto;

(b) na alma. 
A partir dessas observações dos modelos numéricos em relação ao problema físico, uma segunda condição de contorno térmico foi adicionada ao modelo (Figura 8b). Trata-se de um fluxo de calor na superfície do elemento de aquecimento das três regiões, de $1200 \mathrm{~W}$, por $80 \mathrm{~s}$, concomitante com a geração de calor volumétrica (definido a partir de ajuste do perfil térmico em simulações exploratórias). Com isso, o gradiente de temperatura obtido na direção superfície-centro das três regiões foi positivo e os resultados das simulações estáticas foram coerentes com as tensões residuais medidas experimentalmente, como será apresentado posteriormente.

Os resultados dos modelos térmicos, visando simular os ciclos térmicos da soldagem por FBW no trilho intermediário, são apresentados na Figura 10a. Na Figura 10b são apresentados os ciclos térmicos de três pontos monitorados em diferentes posições no modelo: (i) superfície da alma; (ii) superfície superior do boleto; e (iii) superfície inferior do patim, todos os três pontos sobre a linha central. Como pode-se observar, a alma apresentou temperatura máxima superior a $1400{ }^{\circ} \mathrm{C}$, por outro lado, no patim e boleto, as temperaturas de pico foram inferiores a $1350{ }^{\circ} \mathrm{C}$. Estes resultados são semelhantes aos medidos experimentalmente por Weingrill et al. [14] durante a soldagem por centelhamento de trilhos com perfil semelhante.
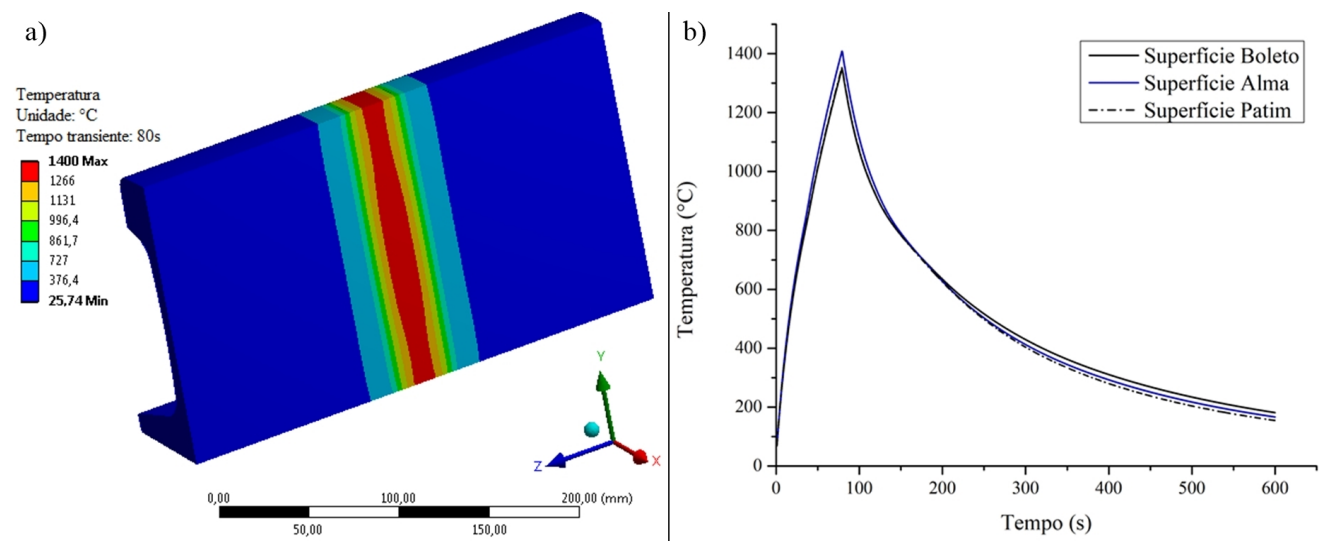

Figura 10. Distribuição de temperaturas em junta soldada obtida pelo MEF (modelo térmico final). (a) Aspecto geral; (b) Ciclos térmicos na superfície superior do boleto, superfície central da alma e superfície inferior do patim.

Outros parâmetros monitorados para ajuste do aporte de calor foram a largura da região aquecida acima de $700{ }^{\circ} \mathrm{C}$ e a taxa de resfriamento. Na Figura 11, pode-se observar que a largura da região aquecida acima de $727^{\circ} \mathrm{C}$ (Ac1) foi superior a $40 \mathrm{~mm}$ na região da alma, valor superior ao obtido nas análises metalográficas para esta região (35mm) [7]. Em relação à taxa de resfriamento na superfície dos modelos, obtiveram-se valores iguais a 2,90 ${ }^{\circ} \mathrm{C} / \mathrm{s}$ e $2,65{ }^{\circ} \mathrm{C} / \mathrm{s}$ para a alma e o boleto, respectivamente, no intervalo entre $800{ }^{\circ} \mathrm{C}$ e $500{ }^{\circ} \mathrm{C}$. Weingrill et al. [14] também simularam a soldagem elétrica por centelhamento de trilhos ferroviários e compararam os valores de taxa de resfriamento simulado e medido experimentalmente. Os valores médios experimentais entre $800^{\circ} \mathrm{C}$ e $500{ }^{\circ} \mathrm{C}$ foram da ordem de $1{ }^{\circ} \mathrm{C} / \mathrm{s}$ e os simulados foram iguais a $3{ }^{\circ} \mathrm{C} / \mathrm{s}$, na região da superfície do boleto. Os autores atribuíram essas diferenças às propriedades do material e/ou condições de contorno utilizadas nas simulações.

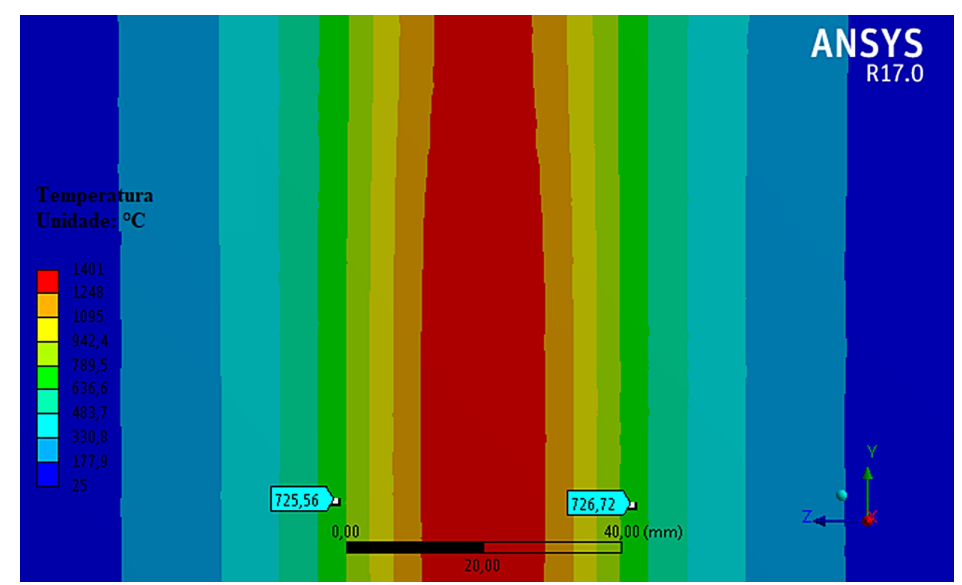

Figura 11. Distribuição de temperaturas na região central da alma durante a temperatura máxima simulada pelo MEF. Os pontos marcados são próximos à temperatura Ac1 do aço [18]. Modelo térmico final, simulação da soldagem por centelhamento elétrico de trilhos ferroviários. 
A partir da comparação entre os resultados de simulação dos ciclos térmicos na temperatura máxima no corte longitudinal da Figura 12a com o resultado da macrografia no trilho soldado por FBW, apresentado na Figura 12b, percebe-se grande semelhança deste com o perfil de temperaturas na seção do trilho, apesar das diferenças entre o valor da ZTA teórica simulada (temperatura acima de Ac1) e medidas macrográficas. Destaca-se maior largura da região aquecida na região da alma e próximo às superfícies do boleto e patim. Resultados muito semelhantes também foram obtidos em relação ao boleto a $10 \mathrm{~mm}$ abaixo da superfície de rolamento (Figura 13).
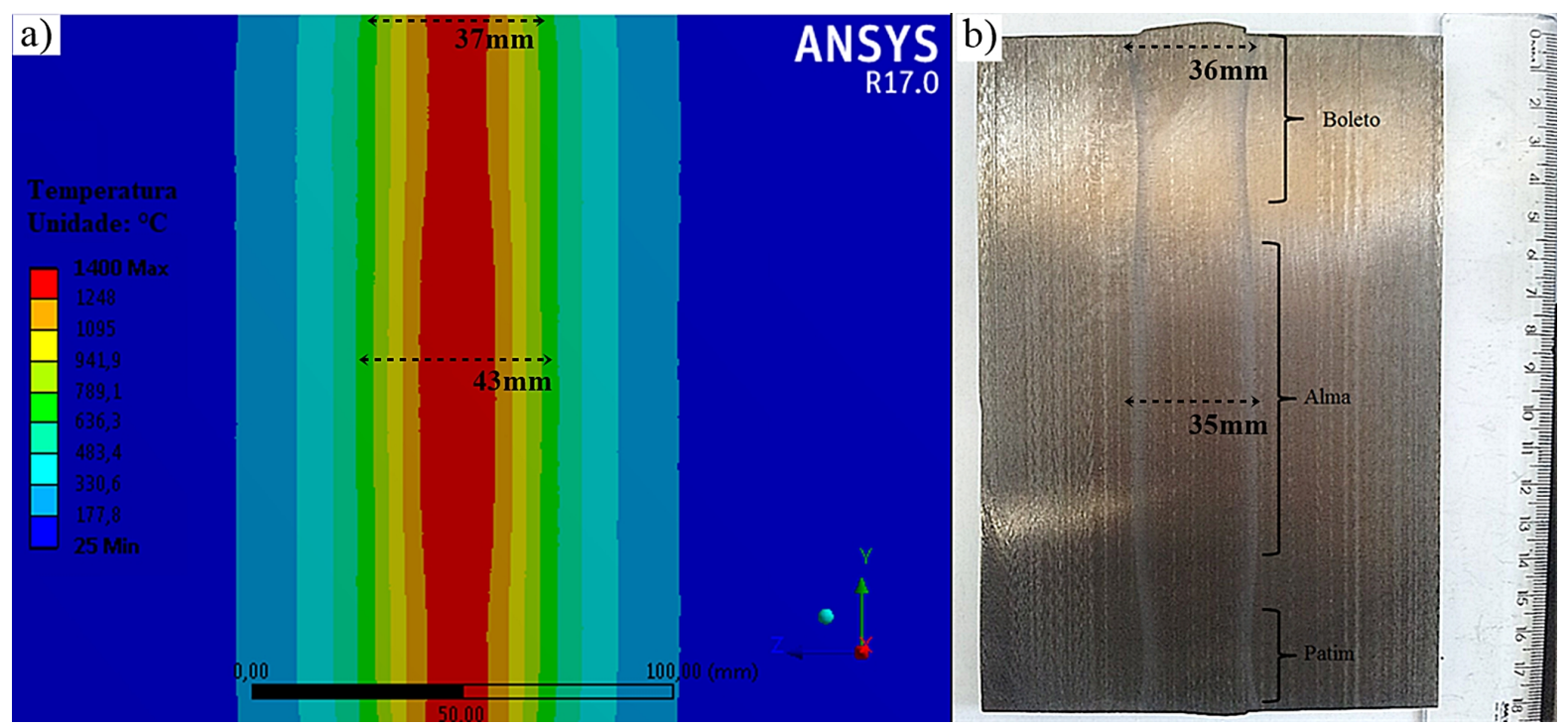

Figura 12. Comparação entre o perfil de temperaturas máximas simuladas pelo MEF durante o processo de soldagem FBW (a) e medidas da largura da ZTA nas três regiões do trilho (b) [7]. Medidas da largura da ZTA visível são apresentadas em (b) e medidas de largura da região aquecida acima de Ac1 são apresentadas em (a).

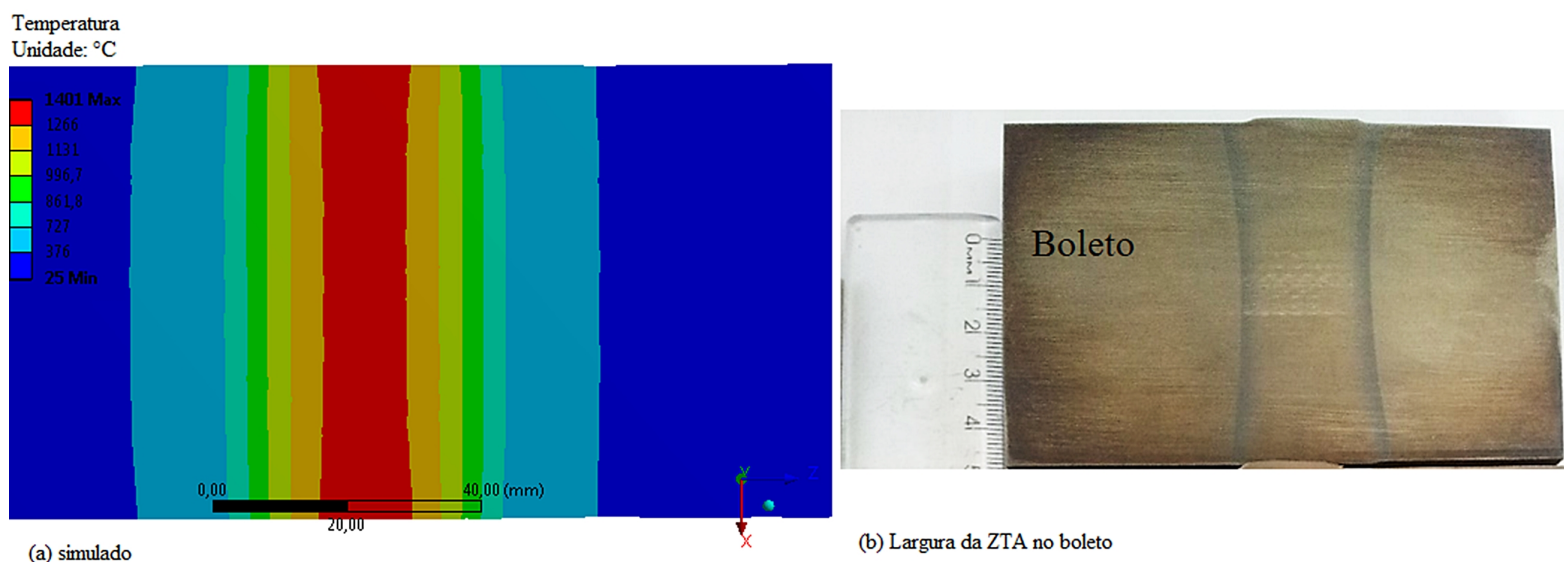

Figura 13. Perfil de temperaturas simuladas pelo MEF durante o processo de FBW (a) e largura da ZTA em corte a 10mm abaixo da superfície de rolamento do boleto (b) [7].

Tawfik et al. [15] utilizaram o software comercial ABAQUS para simular o desenvolvimento de tensões residuais durante a soldagem elétrica por centelhamento em trilhos ferroviários. Como condição de contorno térmica inicial, os autores ajustaram uma distribuição de temperatura com decaimento exponencial em função da distância, com temperatura de pico igual a $1400{ }^{\circ} \mathrm{C}$ na região da linha central e passando por $720^{\circ} \mathrm{C}$ a $25 \mathrm{~mm}$ da linha central, equivalente ao final da ZTA. Ou seja, assim como neste trabalho, estes autores não consideraram temperaturas superiores à temperatura de fusão do aço e a fonte de calor foi ajustada artificialmente de modo a corresponder mais fidedignamente à fonte calor real gerada pelo centelhamento.

A partir dos resultados obtidos aqui, sobretudo em relação aos efeitos da largura da região aquecida e gradientes térmicos desenvolvidos nos modelos sobre o campo de tensões residuais, fica claro que esta abordagem de simulação térmica por elementos finitos pode ser utilizada para avaliar os efeitos de parâmetros do processo de soldagem FBW sobre as tensões 
residuais. Como exemplo, pode-se citar a redução do número de pulsos de pré-aquecimento como proposto por Micenko et al. [27] com o objetivo de reduzir o aporte de calor e, em consequência, a largura da ZTA e as alterações estruturais nas juntas. No entanto, Mutton et al. [3] antecipam que a adoção de ZTA estreita poderia levar a um estado de tensões residuais mais elevado devido à imposição de maiores gradientes de temperatura, como indicam os resultados da análise térmica apresentados neste trabalho.

\subsubsection{Modelo estático estrutural}

Os resultados de tensões residuais normais verticais na alma do trilho são apresentados na Figura 14a, que como observa-se, se assemelham aos reportados na literatura em trabalhos anteriores, ou seja, tensões trativas na região equivalente à ZTA da alma e compressivas fora dela. No entanto, diferente de outros trabalhos publicados na literatura, estes resultados são os primeiros a levar em consideração a diferença de temperatura máxima entre a alma e o boleto e patim. Os três pontos marcados na alma da Figura 14a correspondem aos locais nos quais foram obtidas medidas experimentais de tensões residuais superficiais.

Na Figura 14b, apresentam-se os resultados de tensões residuais normais longitudinais (eixo Z), que também são semelhantes aos reportados na literatura, com tensões normais trativas na região soldada na alma (ZTA) e tensões compressivas na superfície do boleto e patim.
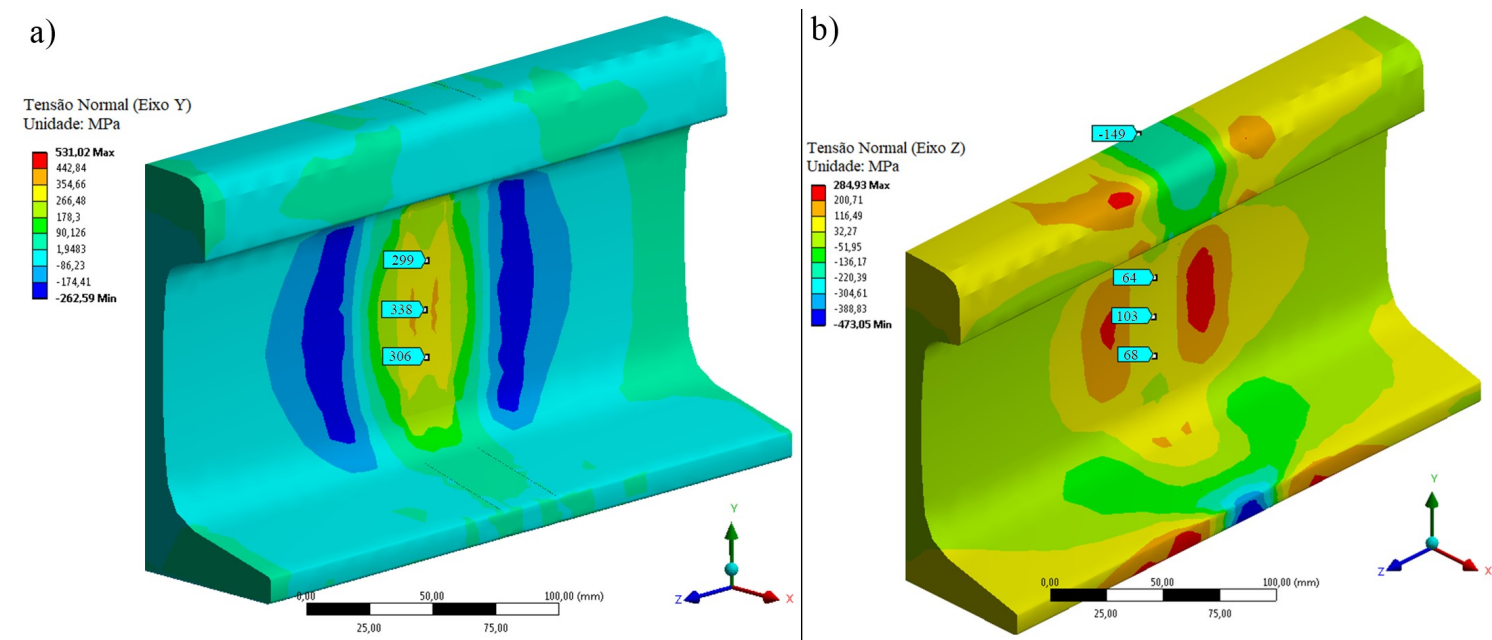

Figura 14. Tensões residuais normais na direção vertical (eixo Y) (a) e direção longitudinal (eixo Z) (b) obtidas por simulação numérica do processo de soldagem por centelhamento.

A comparação entre os valores de tensões residuais obtidos experimentalmente e por simulação nas regiões de medida na superfície da alma e boleto são apresentadas nas Figuras 15a-c, para os sentidos vertical, longitudinal e transversal (Eixo X), respectivamente. Pode-se observar uma significativa correspondência entre os resultados experimentais e numéricos.

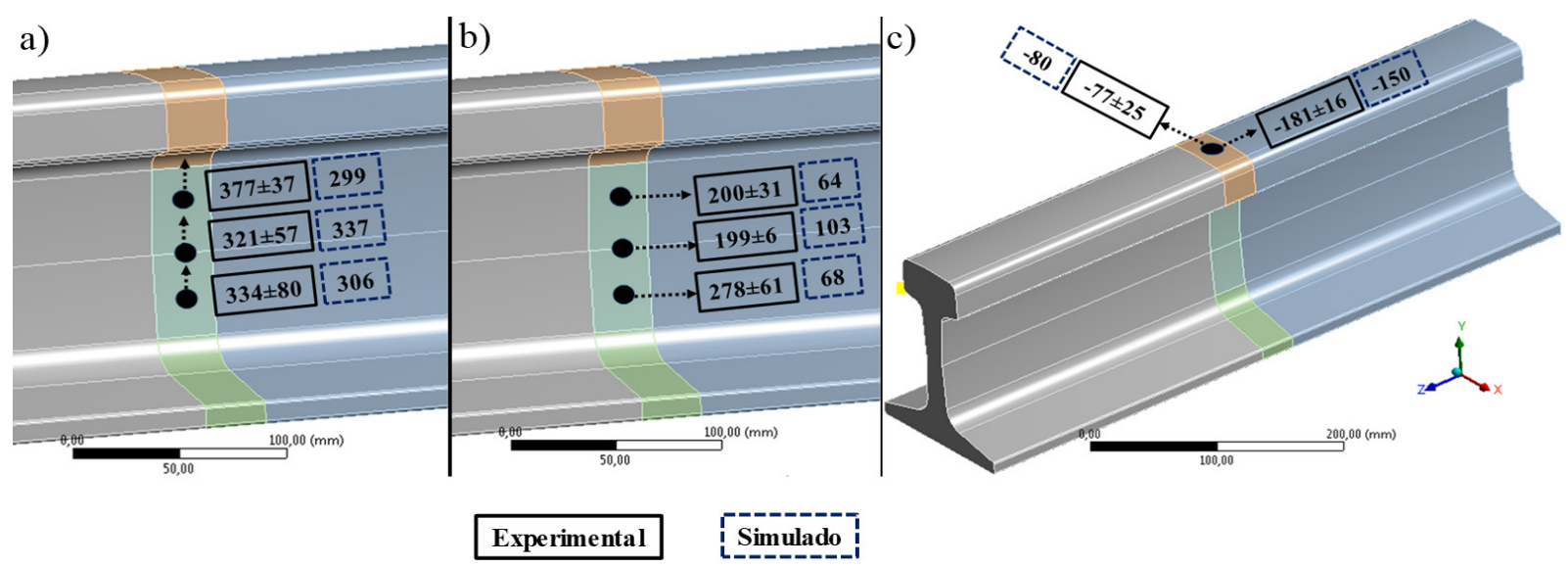

Figura 15. Comparação entre os valores de tensões residuais normais obtidos por simulação (MEF) e experimentais (obtidos pela técnica do furo). (a) Tensões verticais na alma; (b) tensões longitudinais na alma; (c) tensões longitudinais e transversais no boleto. 
Diferenças entre os valores de tensões residuais obtidos experimentalmente e calculados em modelos numéricos por elementos finitos também foram reportados por todos os autores que já trataram deste tema na soldagem de trilhos por centelhamento elétrico [5,10,11,15-17]. Os motivos para as diferenças incluem a simplificação dos modelos numéricos, por exemplo, a não consideração de fenômenos como recristalização e outros efeitos da deformação ao final do processo de soldagem por FBW; o não conhecimento preciso dos ciclos térmicos envolvidos em todas as regiões dos trilhos; simplificações no modelo dos materiais, etc. Portanto, considerando-se que o processo de soldagem em questão é um fenômeno complexo por natureza e que a estratégia de modelagem necessariamente envolve simplificações, resultados idênticos entre os medidos e simulados não podem ser esperados.

Outro ponto de discussão sobre o modelamento do processo de soldagem por centelhamento de trilhos ferroviários que não foi tratado na literatura é sobre as condições de contorno do modelo mecânico. Durante o processo de soldagem, um dos trilhos é fixado por meio do eletrodo e tem todos os seus graus de liberdade restringidos, no entanto, a outra metade é fixada em um atuador hidráulico, responsável por produzir movimentos no sentido longitudinal e, ao final do processo, aplicar o esforço de forjamento. Portanto, do ponto de vista de deslocamento longitudinal (eixo Z nos modelos) não há restrição perfeita como condição de contorno, em outras palavras, não se conhece a resistência ao deslocamento longitudinal nas duas extremidades do modelo. Todos os trabalhos já publicados sobre o tema não aplicam restrição de movimento longitudinal nas duas faces dos modelos, mesma estratégia adotada neste trabalho. Esta pode ser uma das origens das diferenças nos valores de tensões residuais longitudinais experimentais e simuladas, Figura 15b.

As componentes de tensões residuais normais verticais na região da alma são as mais importantes para explicar o desenvolvimento de fraturas por fadiga do tipo $\operatorname{HSW}[5,28]$. Este estado de tensão residual geralmente está associado à presença de concentradores de tensão na superfície da alma, decorrentes de corte inadequado de rebarbas [7] e, somado ao carregamento dos trilhos devido à passagem de composições, sobretudo em curvas, leva à nucleação e crescimento precoce de trincas por fadiga, como descrito por Godefroid et al. [8]. Portanto, a metodologia de simulação proposta aqui, sobretudo os modelos térmicos que consideraram as diferenças de aporte de calor na alma em relação ao boleto e patim, pode ser muito útil para previsão de vida em fadiga das juntas soldadas por FBW, ao se considerar as componentes verticais de tensões residuais na superfície da alma e determinar os locais críticos para nucleação de trincas por fadiga.

Os resultados obtidos na caracterização estrutural apresentados em trabalho anterior [7], que indicaram maior largura da ZTA na alma e em regiões superficiais do boleto e patim, além dos resultados de tensões residuais e dos modelos termomecânicos que, pela primeira vez levaram em consideração a diferença de temperaturas entre as três regiões do trilho e foram comparados a medidas macrográficas, corroboram a hipótese levantada por Mansouri e Monshi [6]. Ou seja, a origem das elevadas tensões residuais verticais na alma de juntas de trilhos ferroviários soldados por FBW pode ser resultado do maior aporte de calor nesta região em relação ao boleto e patim.

\section{Conclusões}

- A partir da aplicação da técnica do furo central com extensometria, tensões residuais normais trativas superiores a $300 \mathrm{MPa}$ foram obtidas na superfície da alma na direção vertical. No sentido longitudinal, obtiveram-se valores superiores a 200MPa, também em tração. Por outro lado, a superfície do boleto apresentou estado de tensão caracterizado por compressão na direção longitudinal (181MPa) e transversal (77MPa);

- $\quad$ Os resultados de tensões residuais obtidos nas juntas de trilho intermediário seguiram a mesma tendência de estudos anteriores, com tensões normais trativas nos sentidos longitudinal e transversal na região da alma e tensões compressivas no boleto;

- As regiões com maior razão superfície/volume apresentaram maior aporte térmico e, consequentemente, maior largura da ZTA. A maior largura da ZTA na alma é um dos fatores que justifica o desenvolvimento de elevadas tensões residuais trativas no sentido vertical nesta região;

- Simulações computacionais termomecânicas por elementos finitos possibilitaram a reconstituição do processo de soldagem por centelhamento e revelam-se, portanto, extremamente úteis na avaliação e interpretação do desenvolvimento de tensões residuais nesse processo;

- $\quad$ Os resultados dos modelos térmicos indicam que a fonte de calor utilizada para simular a soldagem FBW em trilhos ferroviários foi mais adequadamente descrita por meio de uma fonte volumétrica de calor. Mesmo utilizando fonte de calor artificialmente ajustada, os resultados de perfis térmicos e tensões residuais foram próximos aos obtidos experimentalmente, e podem ser utilizados para prever características das juntas, como largura da ZTA e pontos críticos para nucleação de trincas por fadiga. 


\section{Agradecimentos}

À Empresa VLI-FCA por ceder gentilmente as amostras e ao Centro de Desenvolvimento da Tecnologia Nuclear (CDTN) pelo auxílio com as medidas de tensões residuais.

\section{Referências}

[1] Plu J, Bondeux S, Boulanger D, Heyder R. Application of fracture mechanics methods to rail design and maintenance. Engineering Fracture Mechanics. 2009;76(17):2602-2611. http://dx.doi.org/10.1016/j.engfracmech.2009.02.025.

[2] Limberger IF. Estudo da propagação de trincas transversais por fadiga em trilhos ferroviários [tese de doutorado]. Porto Alegre: Programa de Pós-graduação em Engenharia de Minas, Metalúrgica e Materiais, Universidade Federal do Rio Grande do Sul; 2000.

[3] Mutton P, Cookson J, Qiu C, Welsby D. Microstructural characterization of rolling contact fatigue damage in flashbutt welds. Wear. 2016;366-367:368-377. http://dx.doi.org/10.1016/j.wear.2016.03.020.

[4] Zerbst U, Schödel M, Heyder R. Damage tolerance investigations on rails. Engineering Fracture Mechanics. 2009;76(17):2637-2653. http://dx.doi.org/10.1016/j.engfracmech.2008.04.001.

[5] Tawfik D, Mutton PJ, Chiu WK. Experimental and numerical investigations: alleviating tensile residual stress in flash-butt welds by localized rapid post-weld heat treatment. Journal of Materials Processing Technology. 2008;196(1-3):279-291. http://dx.doi.org/10.1016/j.jmatprotec.2007.05.055.

[6] Mansouri $\mathrm{H}$, Monshi A. Microstructure and residual stress variations in weld zone of flash-butt welded railroads. Science and Technology of Welding and Joining. 2004;9(3):237-246. http://dx.doi.org/10.1179/136217104225012201.

[7] Porcaro RR, Lima DAP, Faria GL, Godefroid LB, Cândido LC. Microestrutura e propriedades mecânicas de um aço para trilhos ferroviários soldado por centelhamento. Soldagem e Inspeção. 2017;22(1):59-71. http://dx.doi.org/10.1590/0104-9224/si2201.07.

[8] Godefroid LB, Faria GL, Candido LC, Viana TG. Failure analysis of recurrent cases of fatigue fracture in flash butt welded rails. Engineering Failure Analysis. 2015;58:407-416. http://dx.doi.org/10.1016/j.engfailanal.2015.05.022.

[9] Mutton P. Fatigue damage in rails and rail welds under high axle load conditions. In: Anais do 11 o Congresso Internacional de Fadiga; 2014; Melbourne, Austrália. Melbourne: RMIT University; 2014.

[10] Skyttebol A, Josefson BL, Ringsberg JW. Fatigue crack growth in a welded rail under the influence of residual stresses. Engineering Fracture Mechanics. 2005;72(2):271-285. http://dx.doi.org/10.1016/j.engfracmech.2004.04.009.

[11] Ma N, Cai Z, Huang H, Deng D, Murakawa H, Pan J. Investigation of welding residual stress in flash-butt joint of U71Mn Rail steel by numerical simulation and experiment. Materials \& Design. 2015;88:1296-1309. http://dx.doi.org/10.1016/j.matdes.2015.08.124.

[12] Skyttebol A, Josefson BL. Numerical simulation of flash-butt-welding of railway rails. In: Proceedings of the 7th Mathematical Modelling of Weld Phenomena; 2004; Graz, Austria. Graz: TU Graz Publishing; 2004.

[13] Haibatollahi SP, Tehrani PH. Prediction of residual stress distribution in flash butt welded rails using electro-thermo-mechanical simulation. International Journal of Vehicle Structures and Systems. 2013;5(1):53-57. http://dx.doi.org/10.4273/ijvss.5.2.02.

[14] Weingrill L, Krutzler J, Enzinger N. Temperature field evolution during flash butt welding of railway rails. Materials Science Forum. 2017;879:2088-2093. http://dx.doi.org/10.4028/www.scientific.net/MSF.879.2088.

[15] Tawfik D, Mutton PJ, Chiu WK. Transient thermal stress analysis on rapid post-weld heat treatments applied to flash butt welded rails. Science and Technology of Welding and Joining. 2006;11(3):326-336. http://dx.doi.org/10.1179/174329306X107629.

[16] Cai Z, Nawafune M, Ma N, Qu Y, Cao B, Murakawa H. Residual stresses in flash butt welded rail. Transactions of Joining and Welding Research Institute. 2011;40:79-87.

[17] Ghazanfari M, Tehrani PH. Experimental and numerical investigation of the characteristics of flash-butt joints used in continuously welded rails. Proceedings of the Institution of Mechanical Engineers, Part F: Journal of Rail and Rapid Transit. 2019:1-15. http://dx.doi.org/10.1177/0954409719830189.

[18] Porcaro RR, Faria GL, Godefroid LB, Apolonio GR, Cândido LC, Pinto ES. Microstructure and mechanical properties of a flash butt welded pearlitic rail. Journal of Materials Processing Technology. 2019;270:20-27. http://dx.doi.org/10.1016/j.jmatprotec.2019.02.013.

[19] American Railway Engineering and Maintenance-of-Way Association. Manual of railway engineering and maintenance of way association. Maryland: AREMA; 2013.

[20] American Society for Testing and Materials. E837: standard test method for determining residual stresses by the role drilling strain-gage method. Philadelphia: ASTM; 2013. 16 p.

[21] Bäker M. How to get meaningful and correct results from your finite element model. Ithaca: Cornell University; 2018. 26 p. [access 30 jan. 2019]. Available from: https://arxiv.org/abs/1811.05753

[22] Grishin A. Modeling thermal expansion in ANSYS. 2017. [access 6 apr. 2018]. Available from: https://www.padtinc.com/blog/wpcontent/uploads/2017/07/PADT-ANSYS-Secant_vs_Instantaneous_CTE-2017_07_05.pdf 
[23] ANSYS Inc. Product launcher release 17.0: ANSYS17.0 Help. Pennsylvania; 2016.

[24] Alves A Fo. Elementos finitos: a base da tecnologia CAE: análise não linear. 1. ed. São Paulo: Érica; 2012. 320 p.

[25] Vishay Precision Group. Measurement of residual stresses by the hole-drilling strain gage method. 2010. 16 p. Tech note TN-503. [access 30 jan. 2019]. Available from: http://www.vishaypg.com/docs/11053/tn503.pdf

[26] Yan S, Chen H, Gou G, Li D, Liu Y, Zhu Z. Research on measurement of residual stresses in flash-butt-weld using X-ray diffraction. Advanced Materials Research. 2011;291-294:934-940. http://dx.doi.org/10.4028/www.scientific.net/AMR.291-294.934.

[27] Micenko P, Muruganant A, Huijun L, Xiaofeng X. Double dip hardness profiles in rail weld heat-affected zone: literature and research review report. Brisbane: CRC for Rail Innovation; 2013. Final Report, Project name: Improvements to Railway Welding.

[28] Farhangi H, Mousavizadeh SM. Horizontal split-web fractures of flash butt welded rails. In: Proceedings of the 8th International Fracture Conference; 2007; Istanbul, Turkey. Turkey: Yildiz Technical University; 2007. p. 509-517. 